\title{
Analysis of geopolymer concrete columns
}

Prabir Kumar Sarker, Lecturer, Department of Civil Engineering, Curtin University of Technology, Perth, Western Australia, Phone: +61 89266 7568, Fax: +61 89266 2681, Email: p.sarker@curtin.edu.au

\begin{abstract}
Ordinary portland cement (OPC) has been traditionally used as the binding agent in concrete. However, it is also necessary to search for alternative low-emission binding agents for concrete to reduce the environmental impact caused by manufacturing of cement. Geopolymer, also known as inorganic polymer, is one such material that uses by-product material such as fly ash instead of cement. Recent research has shown that fly ash-based geopolymer concrete has suitable properties for its use as a construction material. Since the strength development mechanism of geopolymer is different from that of OPC binder, it is necessary to obtain a suitable constitutive model for geopolymer concrete to predict the loaddeflection behaviour and strength of geopolymer concrete structural members. This paper has investigated the suitability of using an existing stress-strain model originally proposed by Popovics for OPC concrete. It is found that the equation of Popovics can be used for geopolymer concrete with minor modification to the expression for the curve fitting factor, to better fit with the post-peak parts of the experimental stress-strain curves. The slightly modified set of stress-strain equations was then used in a nonlinear analysis for reinforced concrete columns. A good correlation is achieved between the predicted and measured ultimate loads, load-deflection curves and deflected shapes for twelve slender test columns.
\end{abstract}

Keywords: Column; geopolymer concrete; fly ash; stress-strain relationship. 


\section{Introduction}

Concrete is the most widely used construction material in the world. Ordinary portland cement (OPC) has been traditionally used as the binding agent for concrete. The worldwide consumption of concrete is estimated to increase due to the increase of infrastructure especially in countries such as India and China [1]. The amount of carbon dioxide released during the manufacturing process of OPC is in the order of one ton for every ton of OPC produced. Globally, the OPC production contributes about $7 \%$ of the world's carbon dioxide. This is adding about 1.6 billion tons of carbon dioxide into the atmosphere [1]. Since it has now become a priority to control the trend of global warming by reducing the carbon dioxide emission, it is appropriate to search for alternative low-emission binding agents for concrete. Geopolymer, also known as inorganic polymer, is one such alternative material that acts as the binding agent in concrete. The geopolymer binder uses by-product materials instead of cement and thus its use by the construction industry will reduce the carbon dioxide emission and the environmental impact of the manufacturing of cement.

Geopolymer is a type of alumino-silicate product obtained from the geochemistry process [2]. The geopolymer binders show good bonding properties and utilize a material such as fly ash or metakaolin as the source of Silicon and Aluminium for reaction by an alkali. In fly ashbased geopolymer binder, fly ash is reacted with an alkaline solution to create an aluminosilicate binder. Geopolymer binders are used together with aggregates to produce geopolymer concrete. Fly ash based geopolymer concrete is a recently developed concrete in which no portland cement is used and the geopolymer paste acts as the only binder. The basic ingredients of fly ash-based geopolymer concrete are fly ash, sodium hydroxide, sodium silicate, fine aggregates and coarse aggregates. However, water and super plasticizer can be added to improve workability of the concrete mixture.

Recent research works [3-9] have studied the properties of heat cured fly ash based 
geopolymer concrete. The results of these studies have shown potential use of geopolymer concrete as a construction material. The studies have shown that geopolymer concrete has the properties of high compressive strength, very little drying shrinkage, low creep, good bond with reinforcing steel, good resistance to acid, sulphate and fire. It was also found from the experimental and analytical works that the performance of geopolymer concrete structural members such as beams and columns was similar to that of OPC concrete members. Other recent studies [10-12] have also reported similar engineering properties of geopolymer concrete which are favourable for its use as a construction material.

Computations of the load-deflection behaviour and the ultimate load capacity of reinforced concrete members need the stress-strain relationship of concrete. Past research works $[10,11$, 13, 14] have determined the experimental values of modulus of elasticity of geopolymer concrete. The experimental results of complete stress-strain behaviour of geopolymer concrete were reported by Hardjito et al. [14]. While the strength development in OPC concrete is because of the hydration reaction of cement with water, the strength development in geopolymer concrete is because of the geopolymerisation reaction between the source of Silicon and Aluminium with the alkaline liquids. Because the strength development mechanism of geopolymer concrete is very different from that of OPC concrete, it is necessary to obtain a suitable expression for the stress-strain relationship of geopolymer concrete. It is also necessary to evaluate the application of the conventional methods of analysis used for OPC concrete structures to geopolymer concrete structural members. This paper has evaluated the suitability of using an existing stress-strain model originally proposed by Popovics [15] for OPC concrete to geopolymer concrete. The slightly modified set of stress-strain equation is used in a nonlinear analysis of reinforced concrete columns [16] to analyze the twelve geoppolymer concrete columns tested by Sumajouw et al. [9]. The calculated ultimate axial loads, load-deflection curves and the deflected shapes of the columns 
are compared with the corresponding experimental results.

\section{Material properties}

\subsection{Modulus of elasticity of geopolymer concrete}

The modulus of elasticity $\left(E_{c}\right)$ of geopolymer concrete was determined by testing cylinder specimens and reported in literature by Fernandez-Jimenez et al. [10], Sofi et al. [11], Hardjito et al. [14]. These test results are shown in Fig. 1 and compared with the predictions by different empirical equations. There were some variations in these reported test results in terms of the ingredients of the test specimens and the test methods used. The test results of Fernandez-Jimenez et al. [10] were measured in accordance with the Spanish Standard UNE 83316. These specimens were made using low calcium fly ash, 12.5 molar $\mathrm{NaOH}, \mathrm{Na}_{2} \mathrm{SiO}_{3}$ of $\mathrm{SiO}_{2}$ to $\mathrm{Na}_{2} \mathrm{O}$ ratio of 3.4 , and coarse and fine aggregates. The test data by Sofi et al. [11] and Hardjito et al. [14] were measured in accordance with the Australian Standard 1012.17 [17]. The test specimens of Sofi et al. [11] were made by using low calcium fly ash from three different sources, slag containing $40 \% \mathrm{CaO}$ by mass and a combination of $\mathrm{NaOH}$ or $\mathrm{KOH}$ and $\mathrm{Na}_{2} \mathrm{SiO}_{3}$ as the alkaline liquid. The specimens did not have any coarse aggregates except the one corresponding to compressive strength of $39 \mathrm{MPa}$. The test specimens by Hardjito et al. [14] used low calcium fly ash, 14 molar $\mathrm{NaOH}, \mathrm{Na}_{2} \mathrm{SiO}_{3}$ with $\mathrm{SiO}_{2}$ to $\mathrm{Na}_{2} \mathrm{O}$ ratio of 2 , and coarse and fine aggregates. The type of coarse aggregates used in these specimens was granite.

It is known that the mechanical properties of geoplymer vary with the chemical composition of the product obtained after the reaction. It was found in the previous studies $[10,11]$ that geopolymer showed different mechanical properties depending on the type of fly ash, and the type and concentration of the alkali used. Usually a higher concentration of the alkali 
dissolves a higher proportion of the fly ash particles. Thus a higher degree of geopolymerisation occurs and a denser microstructure is achieved in the geopolymer matrix. The denser microstructure of the matrix provides better mechanical properties to geopolymer concrete. Also, the mechanical properties of geopolymer are found to improve with the increase in the ratio of $\mathrm{Si}$ to $\mathrm{Al}$ of the reaction product. It can be seen that the ingredients and the mixture proportions varied in the test specimens. Because of the variation in the ingredients and their mixture proportions, scatter is observed in the test data presented in Fig. 1.

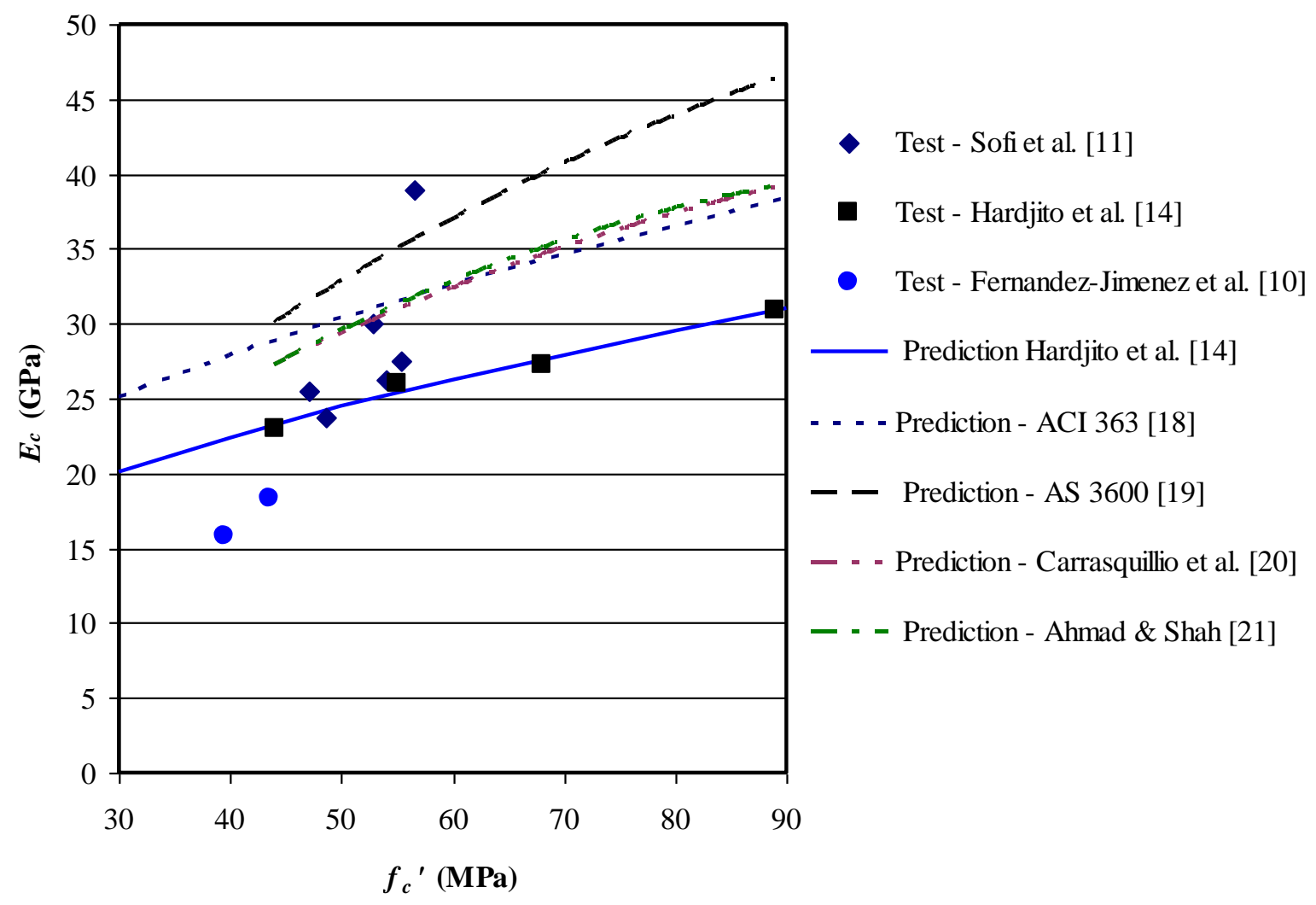

Fig. 1 Modulus of elasticity of geopolymer concrete

While the modulus of elasticity of concrete varies depending on the paste and the type of aggregates, simplified empirical equations in terms of concrete compressive strength $\left(f_{c}\right)$ and concrete density $(\rho)$ are often used for normal-weight concretes. The values of the modulus of 
elasticity calculated by the empirical equations are compared with the test results of geopolymer concrete. Some empirical equations proposed for OPC concrete (Eqs. 1-4) and for geopolymer concrete (Eq. 5) are given below.

American Concrete Institute, ACI 363 [18]:

$E_{c}=3320 \sqrt{f_{c}^{\prime}}+6900$

Australian Standard, AS 3600 [19], within $\pm 20 \%$ :

$E_{c}=0.043 \rho^{1.5} \sqrt{f_{c m}}$

Carrasquilo et al. [20]:

$E_{c}=\left(3320 \sqrt{f_{c}^{\prime}}+6900\right)(\rho / 2320)^{1.5}$

Ahmad and Shah [21]:

$E_{c}=3.38 \rho^{2.5}\left(\sqrt{f_{c}^{\prime}}\right)^{0.65} \times 10^{-5}$

Hardjito et al. [14]:

$E_{c}=2707 \sqrt{f_{c}^{\prime}}+5300$

The prediction equations for the modulus of elasticity of OPC concrete recommended by the Australian Standard AS 3600 [19], Carrasquillo et al. [20] and Ahmad \& Shah [21] are functions of the density of concrete and the concrete compressive strength. The equation proposed by Hardjito et al. [14] for geopolymer concrete is similar to that given by the ACI 363 [18] with different values of the constants. These equations are relatively simple to use since they are expressed as function of concrete compressive strength only. The trend lines through the predicted values of the test results by the five equations (Eqs. 1-5) are shown in Fig. 1. It can be seen that the equations of the ACI 363 [18], AS 3600 [19], Carrasquillo et al. 
[20] and Ahmad \& Shah [21] overestimate most of the test results of geopolymer concrete. The prediction of the modulus of elasticity by Eq. (5) is close to the test results and is considered reasonable taking the variations of test specimens into consideration. Therefore, this equation is used to calculate the modulus of elasticity required for the stress-strain relationship of geopolymer concrete, presented in the next section.

\subsection{Stress-strain relationship of geopolymer concrete}

Experimental data on the stress-strain curves of geopolymer concrete are very limited in literature. Hardjito et al. [14] reported the experimental stress-strain curves of three different mixes of heat cured fly ash-based geopolymer concretes using granite aggregates. These results are shown in Figs. 2 to 4. The expression for the complete stress-strain response of conventional OPC concrete cylinders proposed by Popovics [15] was subsequently modified by Thorenfeldt et al. [22] by introducing a factor $k$ in the equation to ensure a steeper descending part of the curve for high-strength concrete. This expression of Thorenfeldt et al. is selected here to evaluate the suitability of its use for geopolymer concrete by comparing with the experimental stress-strain curves.

The stress-strain relationship of Popovics, modified by Thorenfeldt et al. is given by the following expression:

$$
\frac{f_{c}}{f_{c}^{\prime}}=\frac{\varepsilon_{c}}{\varepsilon_{c}^{\prime}} \cdot \frac{n}{n-1+\left(\frac{\varepsilon_{c}}{\varepsilon_{c}^{\prime}}\right)^{n k}}
$$

where $f_{c}=$ concrete compressive stress, $\varepsilon_{c}=$ strain in concrete, $f_{c}^{\prime}=$ maximum compressive stress in concrete, $\varepsilon_{c}{ }^{\prime}=$ strain when $f_{c}$ reaches $f_{c}^{\prime}$ and $n=$ curve fitting factor. The factor $k$ equals 1 when $\varepsilon_{c} / \varepsilon_{c}$ is less than 1 . Collins and Mitchell [23] suggested that $k$ is given by Eq. (7) for $\varepsilon_{c} / \varepsilon_{c}$ is greater than 1 and the curve fitting factor $n$ is estimated by Eq. (8). 
$k=0.67+\frac{f_{c}^{\prime}}{62}$ when $\frac{\varepsilon_{c}}{\varepsilon_{c}^{\prime}}>1$ in MPa unit

$n=0.8+\frac{f_{c}^{\prime}}{17} \quad$ in MPa unit

Collins et al. [24] recommended that the strain at peak stress $\varepsilon_{c}^{\prime}$ can be found from Eq. (9) by knowing the value of the modulus of elasticity $\left(E_{c}\right)$.

$\varepsilon_{c}^{\prime}=\frac{f_{c}^{\prime}}{E_{c}} \cdot \frac{n}{n-1}$

Equations 6 through 9 were used to calculate the stress-strain curves for the test specimens of Hardjito et al. [14]. Equation 5 was used to calculate $E_{c}$. The calculated stress-strain curves are shown in Figs. 2 to 4. It can be seen from the figures that when the curve fitting factor $n$ is calculated from Eq. (8), the strains corresponding to peak stress $\left(\varepsilon_{c}^{\prime}\right)$ calculated by using Eq. (9) are slightly higher than the measured values and the post peak parts of the calculated stress-strain curves are pushed to the right from the measured curves for all the three cases. It was therefore attempted to obtain a similar modified equation for the curve fitting factor for a better fit between the calculated and the measured stress-strain curves. Equation 10 was thus obtained from trials.

$n=0.8+\frac{f_{c}^{\prime}}{12} \quad$ in MPa unit

The stress-strain curves calculated by using the curve fitting factor given by Eq. (10) are also shown in Figs. 2 to 4. From the comparison between the calculated and measured stress-strain 
curves, it can be seen that Eq. (10) provides a better estimation of the curve fitting factor for the fly ash-based geopolymer concrete. Therefore, Eq. (10) is used to determine the stressstrain relationship of geopolymer concrete cylinders.

However, the strength of concrete in a column differs from that in a cylinder due to their differences in size, vibration during casting, curing, loading rate etc. To take into account these differences, a factor $k_{3}$ is usually applied to the cylinder stress to obtain the concrete stress in a column. ACI committee 363 [25] recommended a constant value of 0.85 for $k_{3}$. Ibrahim and MacGregor [26] analyzed the test results of 49 eccentrically loaded columns for $k_{3}$, which showed a variation of $k_{3}$ from 0.82 to 1.12 , for $f_{c}^{\prime}$ of 40 to $130 \mathrm{MPa}$. Their analysis showed that a value of 0.85 could reasonably be used as a lower bound value of $k_{3}$ for eccentrically loaded columns. MacGregor and Wight [27] used a value of 0.90 for $k_{3}$. This value $k_{3}$ is used in the present analysis to account for the difference in concrete strengths between the compressive cylinder and the column.

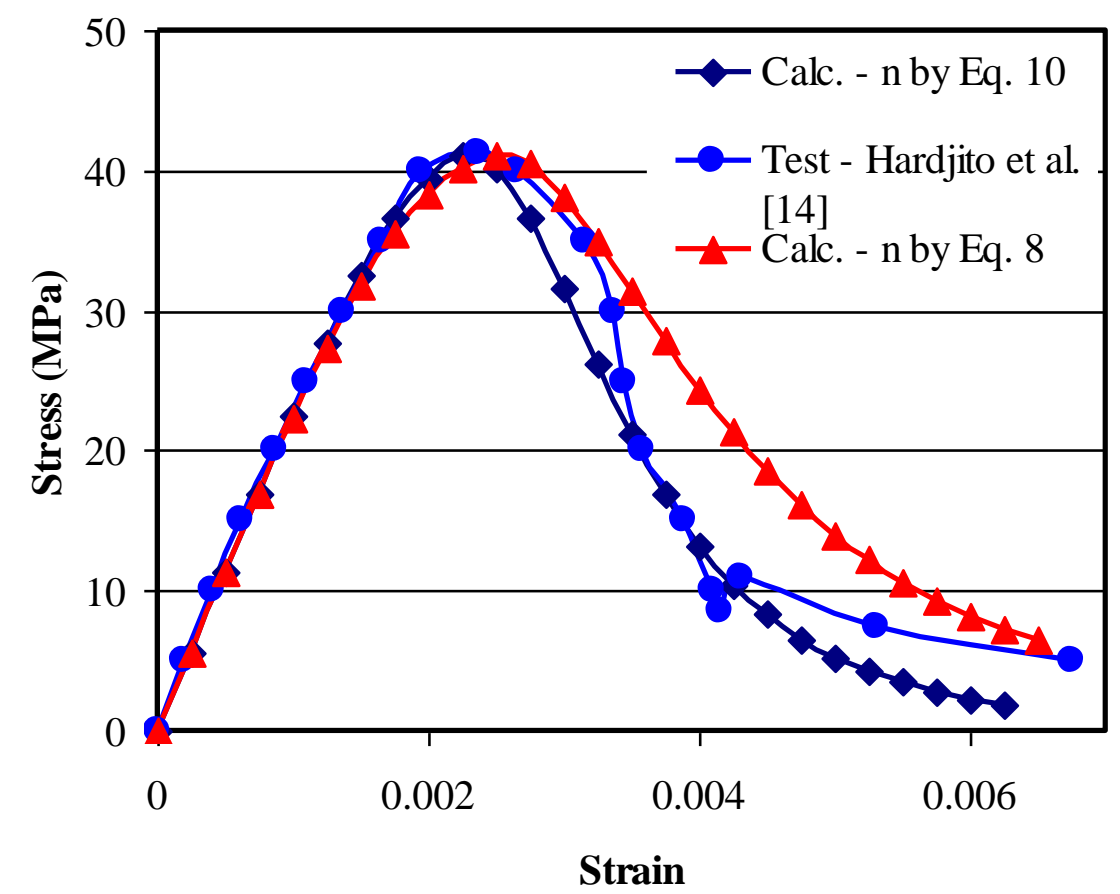

Fig. 2 Stress-strain curve of geopolymer concrete $\left(f_{c}^{\prime}=41 \mathrm{MPa}\right)$ 


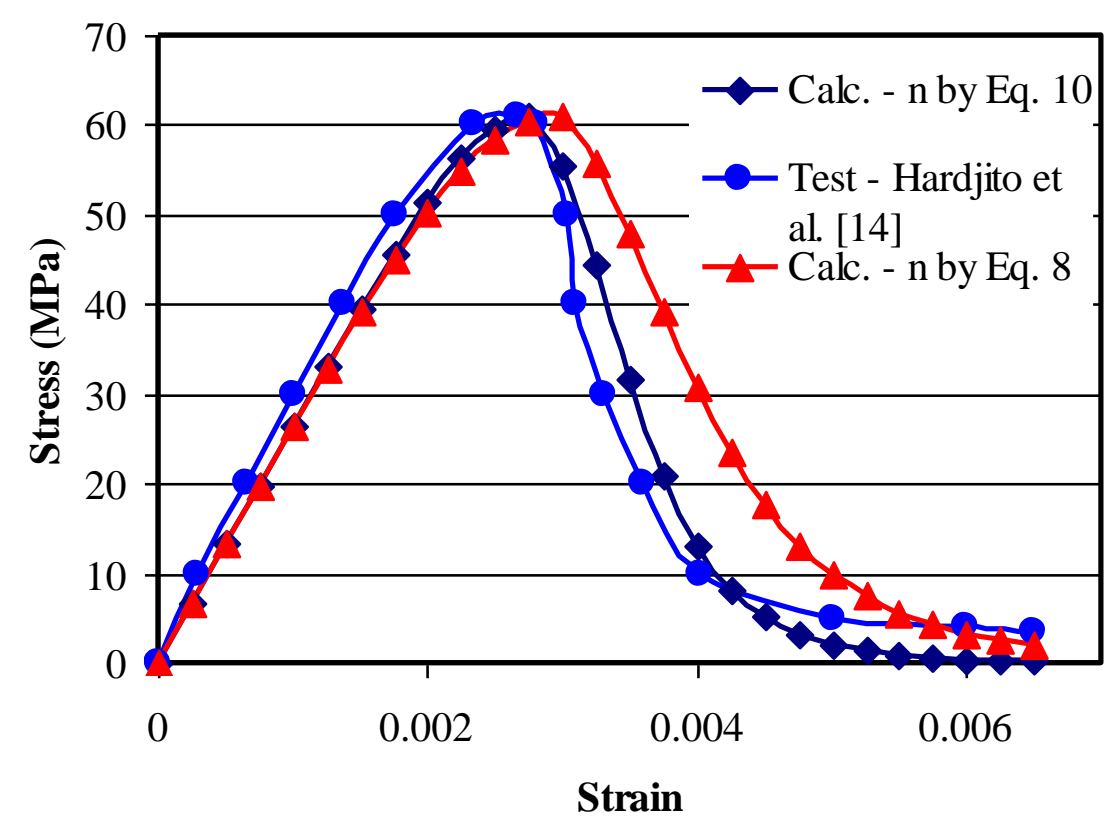

Fig. 3 Stress-strain curve of geopolymer concrete $\left(f_{c}{ }^{\prime}=61 \mathrm{MPa}\right)$

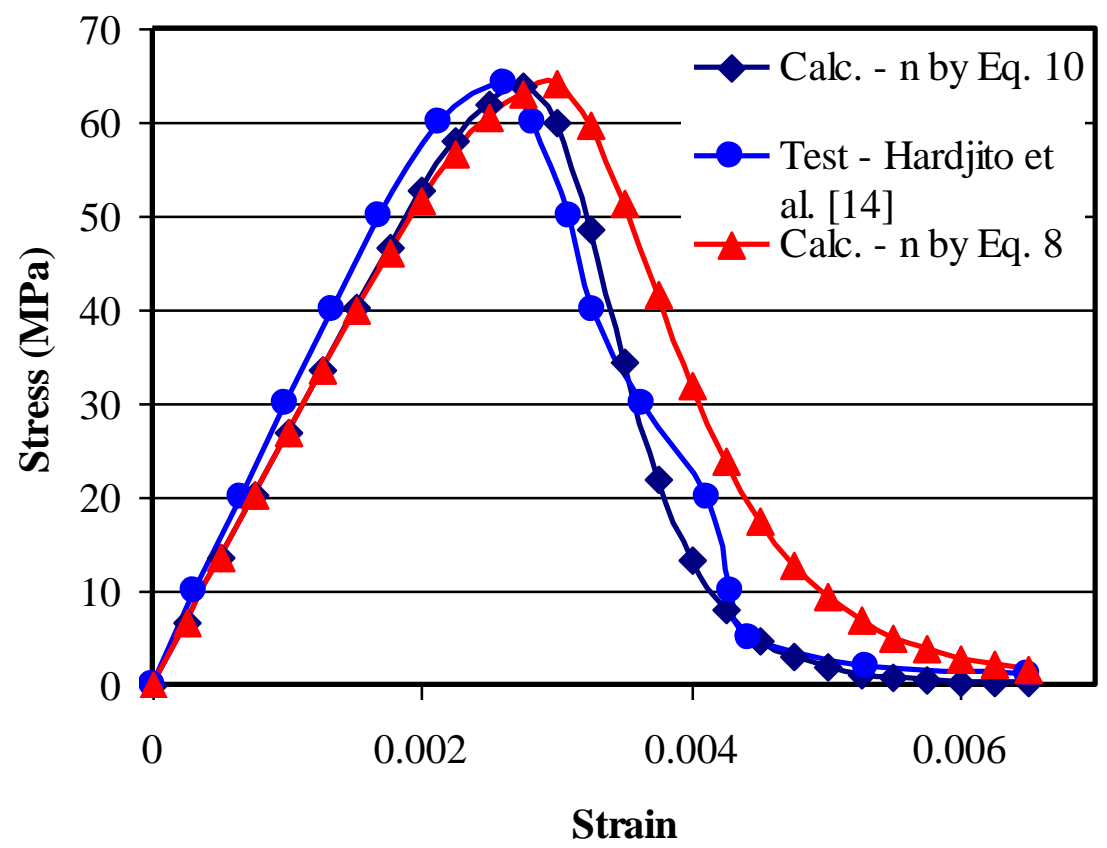

Fig. 4 Stress-strain curve of geopolymer concrete $\left(f_{c}=64 \mathrm{MPa}\right)$ 


\subsection{Stress-strain relationship of reinforcing steel}

The reinforcing steel is assumed to be elastic-perfectly plastic and the stress-strain relationship in tension and compression is taken as follows:

$f_{s}=E_{s} \varepsilon_{s} \quad$ when $\varepsilon_{\mathrm{s}}<\varepsilon_{\mathrm{y}}$

$f_{s}=f_{y} \quad$ when $\varepsilon_{\mathrm{s}} \geq \varepsilon_{\mathrm{y}}$

where $f_{s}=$ stress in steel, $E_{s}=$ modulus of elasticity of steel, $\varepsilon_{s}=$ strain in steel, $\varepsilon_{y}=$ yield strain of steel and $f_{y}=$ yield strength of steel.

\section{Column analysis}

A method of analysis was developed for reinforced concrete columns under combined compression and uniaxial bending with equal or unequal load eccentricities at the ends. It is based on the common assumptions for reinforced concrete members such as preservation of plain sections after bending, perfect bonding between concrete and steel, negligible tensile strength of concrete and initial straightness of the member with prismatic section along the length. The analytical method determines the ultimate axial load capacity of a column using the usual axial load-moment interaction diagram. The section capacity line and the loading line in the interaction diagram are constructed using the moment-thrust-curvature relationship of the cross-section and the load-deflection relationship of the column. The principles used for the development of moment-thrust-curvature and load-deflection relationships are similar to those generally used for reinforced concrete columns [28, 29, 30]. The analytical method uses the actual nonlinear stress distribution in the cross-section to calculate the section capacity. The load path of the column is obtained by calculating the actual deflected shape using the load eccentricities and column slenderness, and is not based on any simplified assumption about the deflected shape. Thus, both material and geometric nonlinearities are taken into 
account to determine the ultimate load capacity of the column. Since the method needs iterations, it is conveniently solved by writing a computer program. The method of analysis is described below.

\subsection{Development of the moment-curvature relationship}

The analysis requires moment-curvature $\left(M_{i}-\kappa\right)$ relationships of the cross section for different axial loads. For this purpose, the column cross section is first divided into number concrete strips of equal height and reinforcement layers, as shown in Fig. 5. The strain and stress distributions, and the calculated axial force and internal moment in the cross-section are also shown in Fig. 5. For a nominated value of axial load $N$, a value of the strain at the extreme compressive fibre of concrete $\varepsilon_{c c}$ is first assumed. For the assumed value of $\varepsilon_{c c}$, a value of the neutral axis depth, $d_{n}$ is guessed. Then the stress in the concrete strips and reinforcing steel layers are obtained using the material constitutive laws described in the previous sections. The stress at the centroid of a concrete strip is assumed to be constant throughout its depth. The forces in all the concrete strips and the steel layers are summed up algebraically to obtain the net axial force $P$ acting on the section.

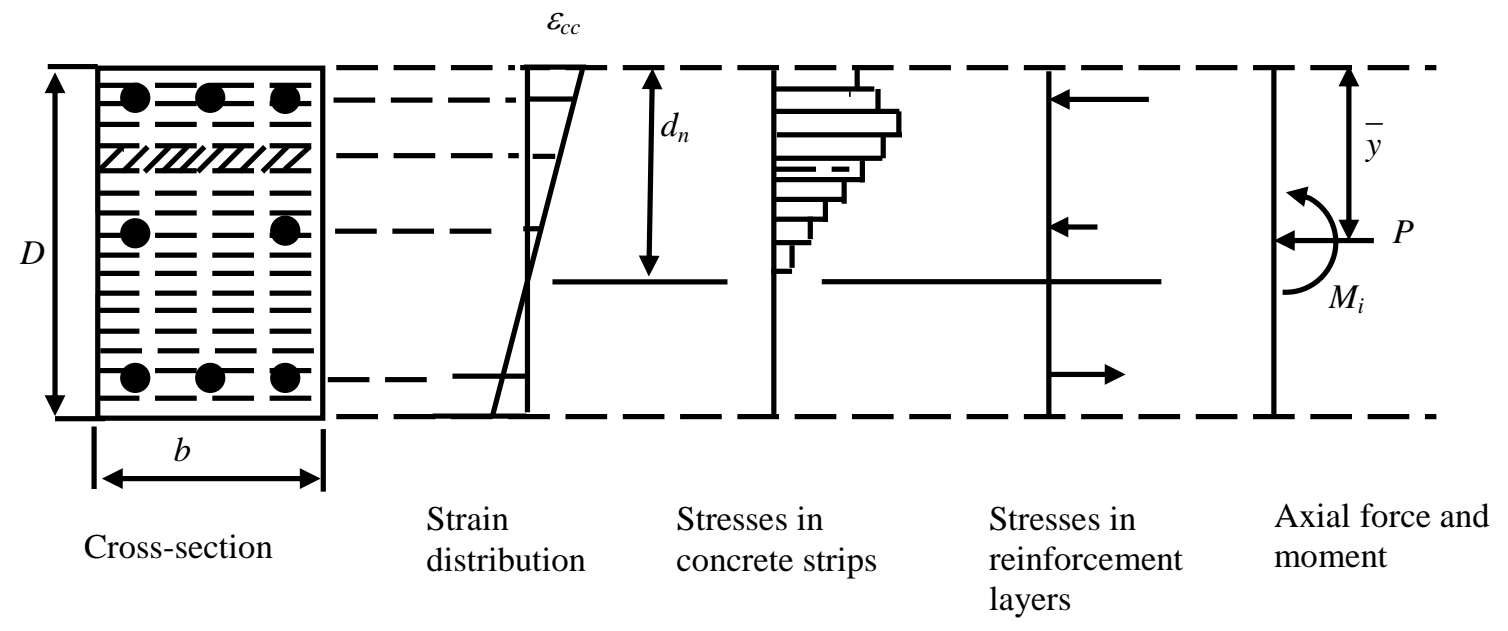

Fig. 5 Cross-section analysis 
The net axial force $P$ is then compared with the nominated value $N$. If the difference between them is not within a prescribed tolerance, a new position of the neutral axis is guessed and the process is repeated. When the correct position of the neutral axis is obtained, the internal moment of the cross-section $M_{i}$ for the current $N$ is calculated. The internal moment of the section is obtained by summing up the moments of the forces of individual concrete strips and reinforcement layers about the plastic centroid. The corresponding curvature is calculated, which is equal to the slope of the strain profile across the cross-section. The complete moment-curvature relationship for the nominated value of the axial load is thus established by incrementing the extreme compressive fibre strain and calculating the corresponding values of moments and curvatures. The moment-curvature relationship is used later to calculate the deflected shape of the column.

\subsection{Column deflected shape}

The column is assumed to be hinged at both the ends and any side sway of the supports is restricted. Therefore, the lateral deflections at the ends are zero. For the purpose of calculating the complete deflected shape for a nominated value of the axial load at a prescribed set of load eccentricities, the column length is divided into a number of rigid segments. The points where two segments are connected to each other are called nodes. Deflection at every node is calculated and thus the complete deflected shape of the column is obtained. Calculation of the node deflections could start from the either end, where the deflection is zero. The provision that the deflection at the other end is also zero is used as a boundary condition for meeting the convergence of the iterative solution.

In the analysis, the slope of the first rigid segment from the starting end is used as a control value and is incremented in every iteration. With the assumed value of the control slope $\theta_{l}$, deflection of the second node is calculated simply by multiplying the slope with the length of 
the rigid segment. Deflections of the subsequent nodes are calculated using the developed moment-curvature relationship of the cross-section for the nominated value of the axial load. Curvature of the deflected column at any node is defined as the rate of change of slope at that node and it can be shown that deflection at any node can be expressed by the following equation [31]:

$v_{j}=\kappa_{j-1}(\Delta L)^{2}+2 v_{j-1}-v_{j-2}$

where $v_{j}=$ deflection at any node $j, \kappa_{j}=$ curvature at node $j$ and $\Delta L=$ length of rigid segment.

For the assumed values of control slope and nominated values of axial load, the node deflections are calculated using Eq. (13) and when the calculated deflection at the last node is close enough to zero, the value of axial load is taken as the correct value for the assumed control slope. Thus the correct values of axial loads and the corresponding node deflections are calculated for the incremented values of control slopes. This gives the deflected shape of the column for an axial load and given load eccentricities.

\subsection{Axial load-moment interaction}

The total external moment $\left(M_{e j}\right)$ at any node $j$ for equal load eccentricities $(e)$ at the column ends is then calculated by the following equation:

$M_{e j}=N\left(e+v_{j}\right)$

The maximum external moment in the column with equal load eccentricities occurs at mid height of the column. The maximum moment capacity (internal) of the cross-section for the nominated axial load is obtained from the moment-thrust-curvature relationship. Thus the load - moment interaction diagram of the column is constructed using the maximum values of external and internal moments corresponding to each axial load. The iterative calculation continues until the maximum external moment reaches the moment capacity of the cross- 
section. The maximum value of the axial load until reaching this point is taken as the ultimate load capacity of the column. If the maximum value of axial load occurs before the loading line reaches the section capacity line, it indicates a buckling failure. Otherwise it is a material failure.

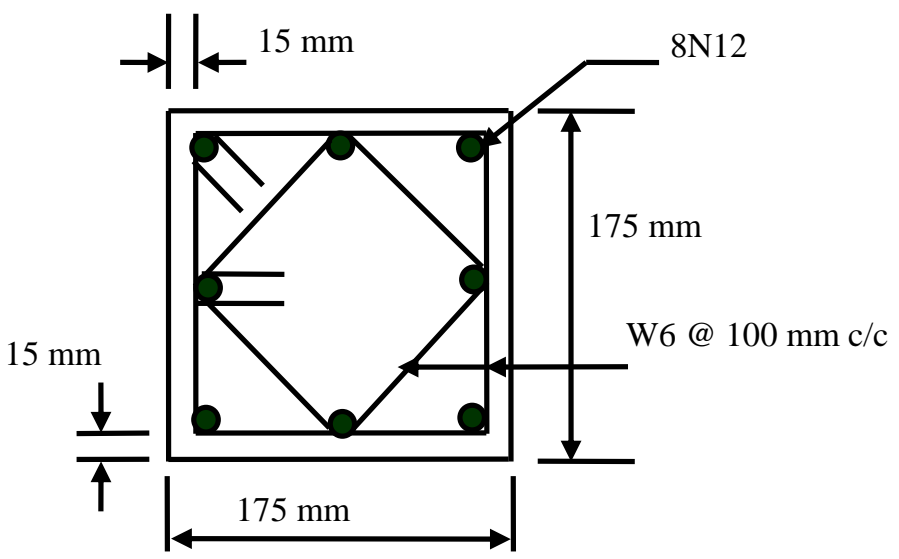

Fig. 6 Typical cross-section of test columns [9]

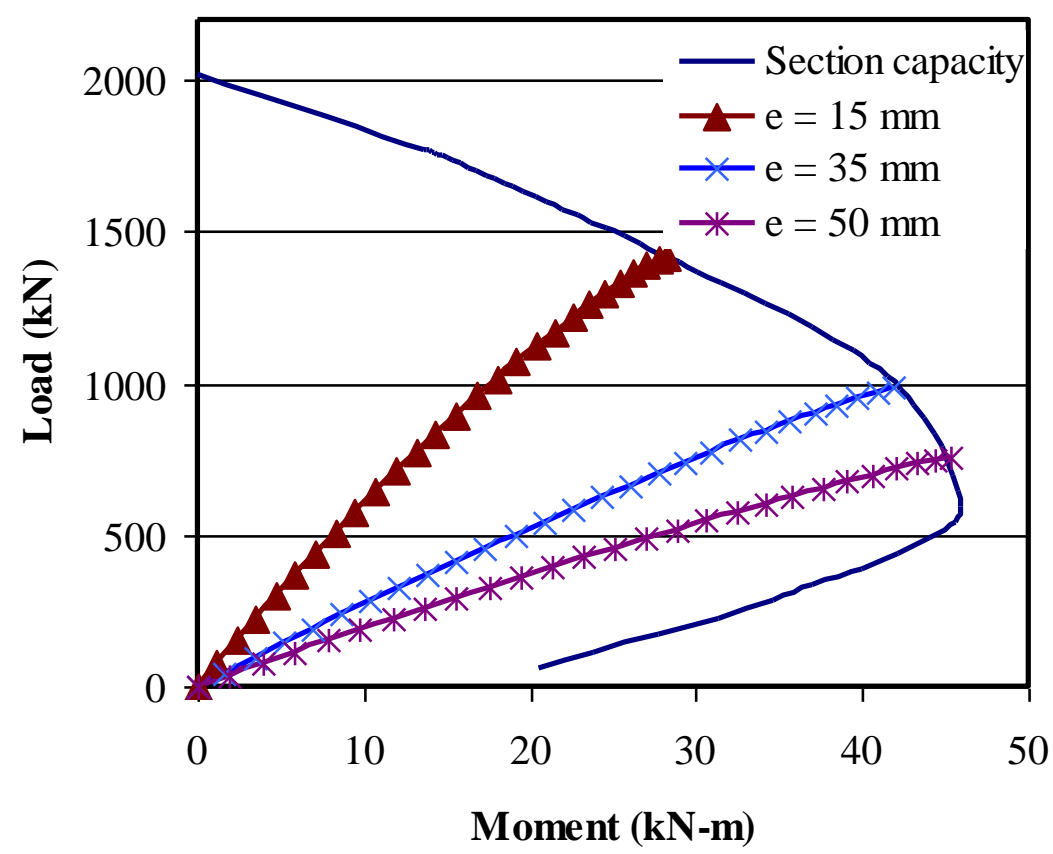

Fig. 7 Load-moment interaction diagrams for GCII-1, GCII-2 and GCII-3 


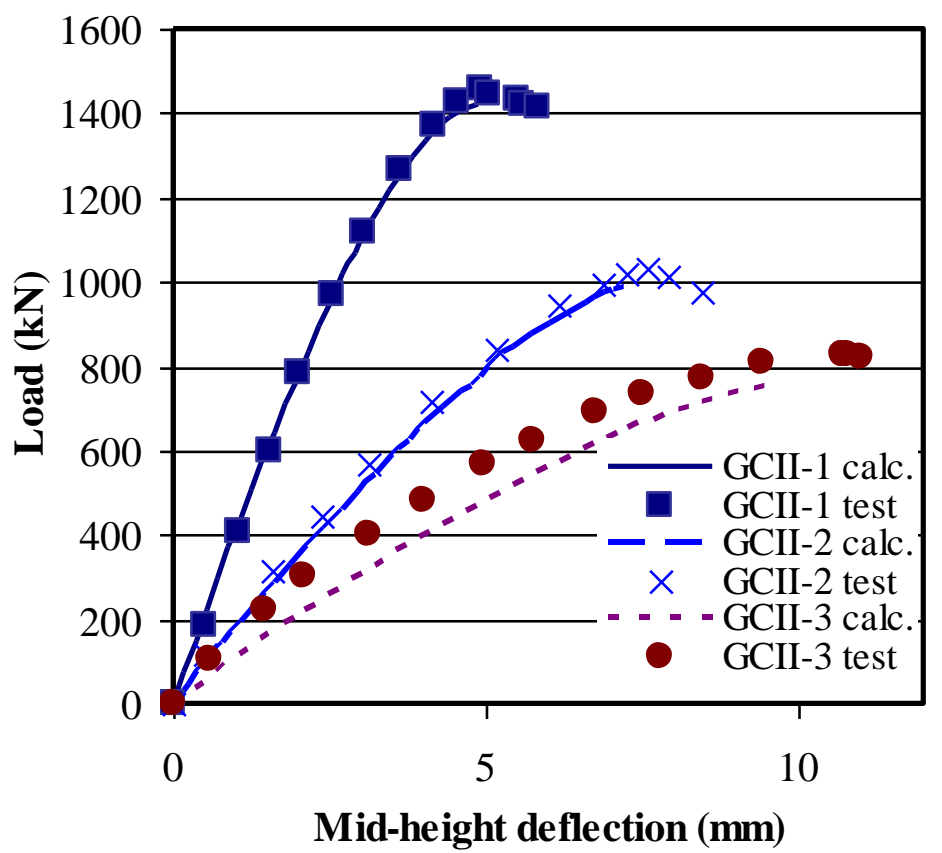

Fig. 8 Load-deflection diagrams for GCII-1, GCII-2 and GCII-3 


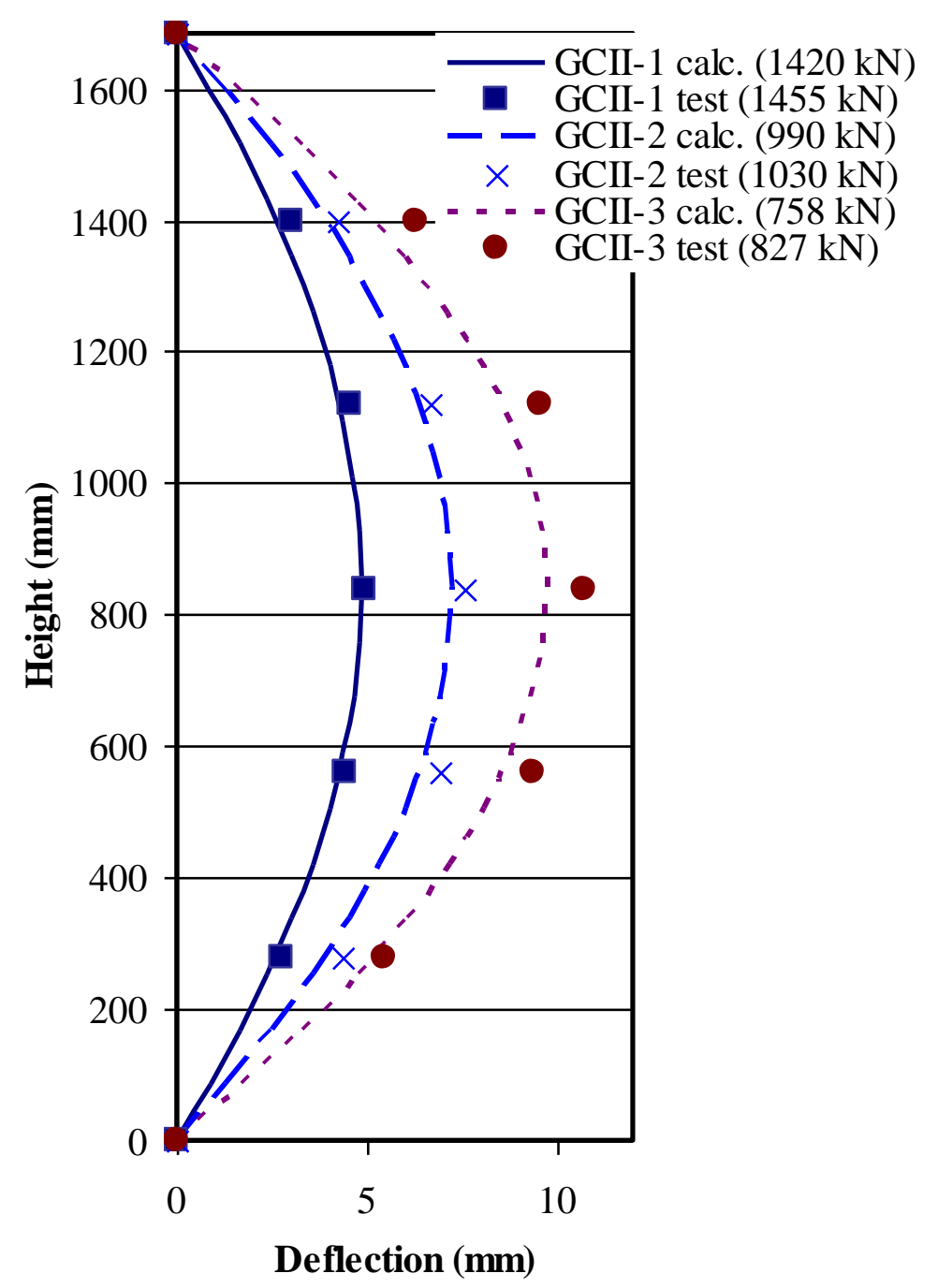

Fig. 9 Deflected shapes at ultimate load for GCII-1, GCII-2 and GCII-3

\section{Comparison of prediction with experimental results}

The analytical method presented in the previous section is implemented in a computer program to perform the column analysis. Since the use of geopolymer in reinforced concrete application is relatively new, very limited test data on reinforced geopolymer concrete is available in literature. The twelve geopolymer concrete columns tested by Sumajouw et al. [9] are analyzed by using the method and the material constitutive laws described in the previous sections. A typical cross-section of these test columns is shown in Fig. 6 and the test 
parameters are given in Table 1. The longitudinal reinforcement of the columns consisted of either 4 or 8 Australian N12 deformed bars. The nominal cross-sectional area of N12 bar is $110 \mathrm{~mm}^{2}$ and the yield strength was $519 \mathrm{MPa}$, as found from tensile strength tests. The lateral closed ties consisted of $6 \mathrm{~mm}$ diameter (W6) hard-drawn steel wires at $100 \mathrm{~mm}$ spacing. Effective length of the columns is taken as the centre to centre distance between the knifeedges, which is equal to the column length plus twice the distance from the column end to the centre of the knife-edge. Length of the test columns was $1500 \mathrm{~mm}$ and the effective length was found to be $1684 \mathrm{~mm}$.

Table 1 Details of the Test Specimens [9]

\begin{tabular}{cccc}
\hline Specimen & $\begin{array}{c}f_{c} \\
(\mathrm{MPa})\end{array}$ & $\begin{array}{c}\text { Longitudinal } \\
\text { reinforcement }\end{array}$ & $\begin{array}{c}e \\
(\mathrm{~mm})\end{array}$ \\
\hline GCI-1 & 42 & $4 \mathrm{~N} 12$ & 15 \\
GCI-2 & 42 & $4 \mathrm{~N} 12$ & 35 \\
GCI-3 & 42 & $4 \mathrm{~N} 12$ & 50 \\
GCI-4 & 43 & $8 \mathrm{~N} 12$ & 15 \\
GCI-5 & 43 & $8 \mathrm{~N} 12$ & 35 \\
GCI-6 & 43 & $8 \mathrm{~N} 12$ & 50 \\
GCII-1 & 66 & $4 \mathrm{~N} 12$ & 15 \\
GCII-2 & 66 & $4 \mathrm{~N} 12$ & 35 \\
GCII-3 & 66 & $4 \mathrm{~N} 12$ & 50 \\
GCII-4 & 59 & $8 \mathrm{~N} 12$ & 15 \\
GCII-5 & 59 & $8 \mathrm{~N} 12$ & 35 \\
GCII-6 & 59 & $8 \mathrm{~N} 12$ & 50 \\
\hline
\end{tabular}

The column is divided into twenty rigid segments in this analysis. Typical load-moment interaction diagrams developed in the analysis, from which the ultimate axial loads are obtained, are shown in Fig. 7. Typical calculated load-deflection diagrams and deflected shapes at the ultimate load are also shown in Figs. 8 and 9 respectively. Table 2 shows the comparison of the calculated and measured values of ultimate load and corresponding midheight deflections for each test column. The mean value of the ratio of test to calculated 
ultimate loads for these twelve columns is 1.03 with a standard deviation of $5 \%$. The mean value of the test - prediction ratios of corresponding mid-height deflections is 1.14 with a standard deviation of $11 \%$. The measured and calculated column load-deflection diagrams and the deflected shapes at ultimate load correlated well, as shown in Figs. 8 and 9.

Table 2 Comparison of Calculated and Test Results

\begin{tabular}{lllllll}
\hline Specimen & \multicolumn{3}{c}{ Test [9] } & \multicolumn{2}{c}{ Prediction } & \multicolumn{2}{c}{ Test-prediction ratio } \\
\cline { 2 - 7 } & $\begin{array}{l}\text { Ultimat } \\
\text { e load } \\
(\mathrm{kN})\end{array}$ & $\begin{array}{l}\text { Mid- } \\
\text { height } \\
\text { deflection } \\
(\mathrm{mm})\end{array}$ & $\begin{array}{l}\text { Ultima } \\
\text { te load } \\
(\mathrm{kN})\end{array}$ & $\begin{array}{l}\text { Mid- } \\
\text { height } \\
\text { deflection } \\
(\mathrm{mm})\end{array}$ & $\begin{array}{l}\text { Ultimate } \\
\text { load } \\
(\mathrm{kN})\end{array}$ & $\begin{array}{l}\text { Mid- } \\
\text { height } \\
\text { deflection } \\
(\mathrm{mm})\end{array}$ \\
\hline GCI-1 & 940 & 5.44 & 992 & 4.50 & 0.95 & 1.21 \\
GCI-2 & 674 & 8.02 & 711 & 6.75 & 0.95 & 1.19 \\
GCI-3 & 555 & 10.31 & 555 & 8.64 & 1.00 & 1.19 \\
GCI-4 & 1237 & 6.24 & 1151 & 4.70 & 1.07 & 1.33 \\
GCI-5 & 852 & 9.08 & 821 & 7.02 & 1.04 & 1.29 \\
GCI-6 & 666 & 9.40 & 651 & 9.02 & 1.02 & 1.04 \\
GCII-1 & 1455 & 4.94 & 1420 & 4.87 & 1.02 & 1.01 \\
GCII-2 & 1030 & 7.59 & 990 & 7.22 & 1.04 & 1.05 \\
GCII-3 & 827 & 10.70 & 758 & 9.74 & 1.09 & 1.10 \\
GCII-4 & 1559 & 5.59 & 1442 & 4.64 & 1.08 & 1.20 \\
GCII-5 & 1057 & 7.97 & 1014 & 7.25 & 1.04 & 1.10 \\
GCII-6 & 810 & 9.18 & 792 & 9.32 & 1.02 & 0.98 \\
& & & & Average & 1.03 & 1.14 \\
& & & Standard deviation & 0.05 & 0.11 \\
\hline
\end{tabular}

\section{Conclusions}

The objective of this study was to find a suitable expression for the stress-strain relationship of geopolymer concrete and to determine the suitability of a nonlinear method for calculation of strength and deflection of reinforced geopolymer concrete columns. From the analytical works, the following conclusions are drawn:

1. Popovics' equation for OPC concrete can be used to calculate the stress-strain curve of low-calcium fly ash-based geopolymer concrete with some modification. Use of Eq. 
(6) with Eqs. (5), (7), (9) and (10) has provided good correlation with the experimental stress-strain curves.

2. The calculated values of the ultimate loads using the described nonlinear method of column analysis have correlated very well with the test results. The mean value of test-prediction ratio is 1.03 and standard deviation is $5 \%$ for the 12 test columns.

3. Calculated mid-height deflections at ultimate load correlated reasonably well with the corresponding test values, with the mean test-prediction ratio of 1.14 and standard deviation of $11 \%$. The calculated load-deflection curves and deflected shapes also correlated well with the corresponding diagrams obtained from tests.

4. Therefore, the analytical method for conventional OPC concrete columns can be used for geopolymer concrete columns with the appropriate stress-strain relationship of geopolymer concrete.

\section{References}

[1] Mehta PK (2001) Reducing the environmental impact of concrete. Concrete International 23(10):61-66

[2] Davidovits J (1994) High-alkali cements for $21^{\text {st }}$ century concretes. Concrete Technology Past, Present and Future. ACI Special Publication, SP 144, Farmington Hills, Michigan, pp383-398.

[3] Hardjito D, Wallah SE, Sumajouw DMJ et al (2004) On the development of fly ashbased geopolymer concrete. ACI Mater J 101(6):467-472

[4] Hardjito D, Wallah SE, Sumajouw DMJ et al (2005) Fly ash-based geopolymer concrete. Aust J Struct Eng 6(1):77 - 86

[5] Rangan BV (2006) Studies on low-calcium fly ash-based geopolymer concrete. Indian 
Concrete Institute J October - December: 9-17

[6] Sarker PK (2004) Making geopolymer concrete using Sarawak fly ash. In: Proceedings of The First International Conference of Asian Concrete Federation, Chiang Mai, Thailand, 28-29 October 2004, pp633-640

[7] Sarker PK, Grigg A and Chang EH (2007) Bond strength of geopolymer concrete with reinforcing steel. In: Zingoni A (ed) Recent Developments in Structural Engineering, Mechanics and Computation, CD ROM, Millpress, the Netherlands, pp1315-1320

[8] Sarker PK and deMeillon T (2007) Residual strength of geopolymer concrete after exposure to high temperature. In: Zingoni A (ed) Recent Developments in Structural Engineering, Mechanics and Computation, CD ROM, Millpress, the Netherlands, pp1566-1571

[9] Sumajouw DMJ, Hardjito D, Wallah SE et al (2007) Fly ash-based geopolymer concrete: Study of Slender Columns. J Mater Sci 42 (9):3124-3130

[10] Fernandez-Jimenez AM, Palomo A and Lopez-Hombrados C (2006) Engineering properties of alkali-activated fly ash concrete. ACI Mater J 103 (2):106-112

[11] Sofi M, van Deventer JSJ, Mendis, PA et al (2007) Engineering properties of inorganic polymer concretes (IPCs). Cem and Conc Res 37:251 - 257

[12] Sofi M, van Deventer JSJ, Mendis PA et al (2007) Bond performance of reinforcing bars in inorganic polymer concretes (IPCs) J Mater Sci 42:3107-3116

[13] Hardjito D and Rangan BV (2005) Development and properties of low calcium fly ashbased geopolymer concrete, Research Report GC1, Faculty of Engineering, Curtin University of Technology, Western Australia. available via http://espace.lis.curtin.edu.au/ 
[14] Hardjito D, Wallah SE, Sumajouw, MJ et al (2005) The stress-strain behaviour of fly ash-based geopolymer concrete. Developments in Mechanics of Structures and Materials. A A Balkema Publishers, The Netherlands, pp831 - 834

[15] Popovics S (1973) A numerical approach to the complete stress-strain curve of concrete. Cem and Conc Res 3:583-599

[16] Sarker PK Rangan BV (2003) Reinforced concrete columns under unequal load eccentricities. ACI Struct J 100 (4):519-528

[17] AS 1012.17 (1997) Determination of static chord modulus of elasticity and poisson's ratio of concrete specimens. Standards Association of Australia, Sydney, Australia

[18] ACI Committee 363(1993) State of the art of high strength concrete, American Concrete Institute, Detroit, USA

[19] AS 3600 (2001) Concrete structures. Standards Association of Australia, Sydney, Australia

[20] Carrasquillo RL, Nilson AS and Slate FO (1981) Properties of high strength concrete subjected to short term loads. ACI J 78:171 - 178

[21] Ahmad SH and Shah SP (1985) Structural properties of high strength concrete and its implication for precast pre-stressed concrete. PCI J 30:92 - 119

[22] Thorenfeldt E, Tomaszewicz A and Jensen JJ (1987) Mechanical properties of high strength concrete and application in design. Proceedings of the Symposium of on Utilization of high strength Concrete, Tapir, Trondheim, 1987, pp149-159

[23] Collins MP, Mitchell D (1991) Prestressed concrete structures. Prentiece-Hall Inc., Englewood Cliffs, New Jersey

[24] Collins MP, Mitchell D and MacGregor JG (1993) Structural design considerations for 
high-strength concrete. Concrete International 15(5):27-34

[25] ACI Committee 363 (1984) State of the art report on high strength concrete. ACI Proc 81(4):364-411

[26] Ibrahim, HHH, and MacGregor JG (1997) Modification of the ACI rectangular stress block for high-strength concrete. ACI Struct J 94(1):40-48

[27] MacGregor JG and Wight JK (2006) Reinforced concrete mechanics and design, $4^{\text {th }}$ ed. In SI units, Prentice Hall

[28] Pfrang EO, Siess CP and Sozen MA (1964) Load-moment-curvature characristics of reinforced concrete cross-sections. ACI J Proc 61(7):763-777

[29] Warner, RF, Rangan BV, Hall AS et al (1998) Concrete structures, Addison Wesley Longman, Australia

[30] Kilpatrick AE (1996) The behaviour of high strength composite concrete columns. PhD Thesis, Curtin University of Technology, Western Australia

[31] Sarker PK (2001) Study of high strength concrete columns. PhD Thesis, Curtin University of Technology, Western Australia 